\title{
Activation of lignocellulosic biomass for higher sugar yields using aqueous ionic liquid at low severity process conditions
}

\author{
Ramakrishnan Parthasarathi ${ }^{1,2}$, Jian Sun ${ }^{1,2}$, Tanmoy Dutta ${ }^{1,2}$, Ning Sun ${ }^{1}$, Sivakumar Pattathil $1^{3,4}$, \\ N. V. S. N. Murthy Konda ${ }^{1}$, Angelo Gabriel Peralta ${ }^{3,4}$, Blake A. Simmons ${ }^{1,2}$ and Seema Singh ${ }^{1,2^{*}}$
}

\begin{abstract}
Background: Concerns around greenhouse gas emissions necessitate the development of sustainable processes for the production of chemicals, materials, and fuels from alternative renewable sources. The lignocellulosic plant cell walls are one of the most abundant sources of carbon for renewable bioenergy production. Certain ionic liquids (ILs) are very effective at disrupting the plant cell walls of lignocellulose, and generate a substrate that is effectively hydrolyzed into fermentable sugars. Conventional ILs are relatively expensive in terms of purchase price, and the most effective imidazolium-based ILs also require energy intensive processing conditions $\left(>140^{\circ} \mathrm{C}, 3 \mathrm{~h}\right.$ ) to release $>90 \%$ fermentable sugar yields after saccharification.

Results: We have developed a highly effective pretreatment technology utilizing the relatively inexpensive IL comprised tetrabutylammonium $\left[\mathrm{TBA}^{+}\right.$and hydroxide $[\mathrm{OH}]^{-}$ions that generate high glucose yields ( 95 \%) after pretreatment at very mild processing conditions $\left(50^{\circ} \mathrm{C}\right)$. The efficiency of $[\mathrm{TBA}][\mathrm{OH}]$ pretreatment of lignocellulose was further studied by analyzing chemical composition, powder X-ray diffraction for cellulose structure, NMR and SEC for lignin dissolution/depolymerization, and glycome profiling for cell wall modifications. Glycome profiling experiments and computational results indicate that removal of the noncellulosic polysaccharides occurs due to the ionic mobility of $[\mathrm{TBA}][\mathrm{OH}]$ and is the key factor in determining pretreatment efficiency. Process modeling and energy demand analysis suggests that this [TBA][OH] pretreatment could potentially reduce the energy required in the pretreatment unit operation by more than $75 \%$.
\end{abstract}

Conclusions: By leveraging the benefits of ILs that are effective at very mild processing conditions, such as [TBA] $[\mathrm{OH}]$, lignocellulosic biomass can be pretreated at similar efficiency as top performing conventional ILs, such as 1-ethyl-3-methylimidazolium acetate $\left[\mathrm{C}_{2} \mathrm{C}_{1} \mathrm{Im}\right][\mathrm{OAc}]$, but at much lower temperatures, and with less than half the IL normally required to be effective. [TBA][OH] IL is more reactive in terms of ionic mobility which extends removal of lignin and noncellulosic components of biomass at the lower temperature pretreatment. This approach to biomass pretreatment at lower temperatures could be transformative in the affordability and energy efficiency of lignocellulosic biorefineries.

Keywords: Aqueous ionic liquid, Pretreatment, Biofuels, Higher sugar yield, Low severity condition

\section{Background}

Lignocellulosic biomass is an abundant renewable resource primarily composed of cellulose, lignin, and

\footnotetext{
*Correspondence: SSingh@|bl.gov

${ }^{2}$ Sandia National Laboratories, Biological and Engineering Sciences Center, Livermore, CA, USA

Full list of author information is available at the end of the article
}

hemicellulose that form a complex composite structure [1-4]. The recalcitrance of this complex composite poses a significant barrier to economical, chemical, or biological conversion technologies that can convert the fermentable sugars present in lignocellulose into advanced biofuels and renewable chemicals [5]. Several physical and/or chemical pretreatment processes have 
been implemented to reduce the recalcitrance of lignocellulosic materials and improve their utilization [6-8]. Conventional pretreatments, such as those that use concentrated or dilute acids and bases, are only effective in producing a substrate capable of generating high fermentable sugar yields using severe process conditions $\left(\sim 120-200{ }^{\circ} \mathrm{C}\right)$. After pretreatment, the recovered substrate is saccharified using enzyme mixtures at $40-80^{\circ} \mathrm{C}$. There is an intricate interplay between the type of pretreatment and fermentable sugar yields achieved (Fig. 1) [6, 9-15]. These higher temperature process technologies increase the energy required, and thereby increase production costs [7]. Generally, temperature of pretreatment process has been set around the range of the glass transition temperature of lignin, thereby impacting the physicochemical properties of lignin and cellulose [16], hemicellulose hydrolysis [17], and cellulose digestion [18].

Certain ionic liquids (ILs) are able to dissolve either lignocellulosic materials or one of its main constituents, such as cellulose, hemicellulose, or lignin [19]. The IL 1-ethyl-3-methylimidazolium acetate $\left(\left[\mathrm{C}_{2} \mathrm{C}_{1} \mathrm{Im}\right][\mathrm{OAc}]\right)$ based pretreatment process typically requires temperatures above $140{ }^{\circ} \mathrm{C}$ for $3 \mathrm{~h}$ reaction time to be effective and typically use pure IL as the pretreatment solvent [10, 12, 20-22]. There have been recent efforts focused on the discovery and demonstration of ILs for the pretreatment/fractionation of lignocellulosic materials at less severe process conditions [23-25]. [OH] based ILs with $\left[\mathrm{C}_{2} \mathrm{C}_{1} \mathrm{Im}\right]$ were used for biochemical synthesis, such as sugars [26], biodiesel [27] and 5-hydroxymethylfurfural $[26,28]$. Studies on quaternary ammonium cations, such as tetrabutylammonium fluoride trihydrate $([\mathrm{TBA}] \mathrm{F})$ [29], tetraethylammonium chloride ([TEA]Cl) [30], and tetrabutylammonium hydroxides $([\mathrm{TBA}][\mathrm{OH}])$ [31] with co-solvents, were reported to dissolve cellulose rapidly at low temperatures. This rapid dissolution of cellulose at

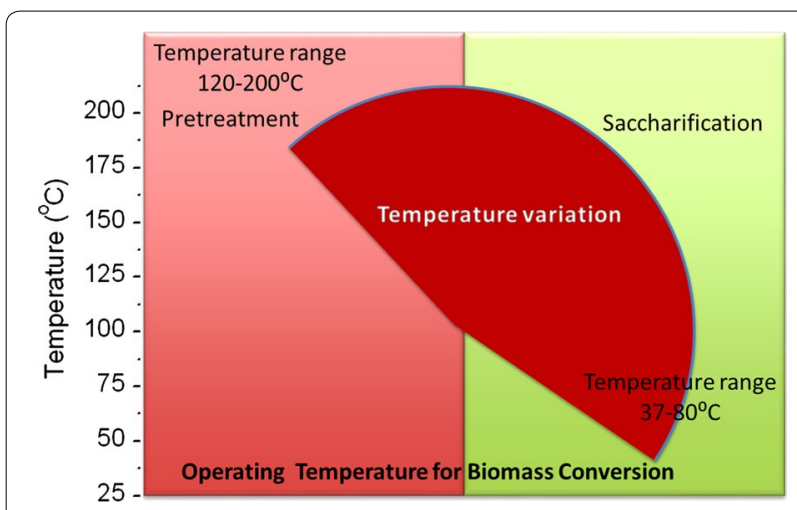

Fig. 1 Temperature variations in a typical biomass pretreatment and saccharification processes low temperatures has been hypothesized to occur due to the strong proton accepting capacity of the anion, even in the presence of water that weakens the association of the hydrogen bonding network and destabilizing the cellulose microstructure.

Recent studies using tetrabutylammonium acetate ([TBA][OAc]) with dimethyl sulfoxide (DMSO) and crown ether (18-crown-6) demonstrated the feasibility of $8 \mathrm{wt} \%$ cellulose dissolution within $5 \mathrm{~min}$ at $40{ }^{\circ} \mathrm{C}$ [32]. Tetrabutylphosphonium hydroxides ([TBP] $[\mathrm{OH}]$ ) containing $30-50 \mathrm{wt} \%$ water can dissolve cellulose at $25{ }^{\circ} \mathrm{C}$ [33], and Ohno and co-workers recently reported the rapid ( $~ 5 \mathrm{~min})$ dissolution of $15 \mathrm{wt} \%$ cellulose in aqueous solutions of $[\mathrm{TBP}][\mathrm{OH}]$ that contained $40-50 \%$ water by weight at room temperature [34]. Zhong et al. reported cellulose isolation from wheat straw using $[\mathrm{TBA}][\mathrm{OH}]$ solutions containing $50 \%$ water at $60{ }^{\circ} \mathrm{C}$ after de-waxed with toluene-ethanol $(2: 1, \mathrm{v} / \mathrm{v})$ and pretreated in boiling water for $2 \mathrm{~h}$ [35]. Unfortunately, from a biorefinery perspective, all of these methods require multi-step treatments, use of co-solvents, water washes and have not been proven on a wide range of "real world" lignocellulosic biomass substrates, such as switchgrass, pine and eucalyptus. The possibility of IL pretreatment at lower operating temperatures may facilitate the development of more affordable and practical pretreatment processes with seamless biomass integrated conversion processes $[3,13,36]$. We report here that the relatively inexpensive $[37][\mathrm{TBA}][\mathrm{OH}]$ processing of lignocellulose can pretreat biomass to similar efficiency as top performing conventional ILs, such as $\left[\mathrm{C}_{2} \mathrm{C}_{1} \mathrm{Im}\right][\mathrm{OAc}]$, but at much lower temperatures, and with less than half the IL normally required to be effective.

\section{Results and discussion}

\section{Compositional analysis and lignin fractionation}

The compositional analysis of switchgrass before and after pretreatment is summarized in Table 1. Solid recovery refers to the mass percentage of biomass (dry weight) recovered from the original biomass load. Three of the major plant cell wall components of switchgrass (i.e., glucan, xylan, and acid-insoluble lignin), were monitored before and after the pretreatment. Untreated dry switchgrass contained $31.9 \%$ glucan, $20.2 \%$ xylan and $20.7 \%$ acid-insoluble lignin. The pretreatment experiments were conducted at different conditions (i.e., $25{ }^{\circ} \mathrm{C}$ for $0.5,1$ and $3 \mathrm{~h} ; 50{ }^{\circ} \mathrm{C}$ for $0.5,1$ and $3 \mathrm{~h}$ ). The solid recovery was obviously decreased with increasing temperature and time. Using the conditions of $50{ }^{\circ} \mathrm{C}$ for $3 \mathrm{~h}$, approximately $48 \mathrm{wt} \%$ of the biomass was recovered, of which $62 \%$ was glucan, $12.7 \%$ was xylan and $10.5 \%$ was lignin. Based on the compositional change, the mass loss is caused by significant removal of lignin, xylan, and/or other soluble 
extractives. While the loss of glucan was approximately $6.5 \mathrm{wt} \%$, the removal of xylan was significantly higher $(\sim 69.8 \mathrm{wt} \%)$. Also, the lignin removal during pretreatment process ( $75.7 \mathrm{wt} \%)$ was comparable with our previous results for switchgrass with 49-87 \% lignin removal after pretreatment with different types ILs at high temperature $\left(140^{\circ} \mathrm{C}\right)[21]$.

\section{Cellulose crystallinity}

$\mathrm{X}$-ray diffraction (XRD) studies were conducted to determine the changes in the crystalline $v s$. noncrystalline components (i.e., amorphous cellulose, hemicellulose and lignin) found in the switchgrass sample, and to monitor the structural changes in these polymers that occur during $[\mathrm{TBA}][\mathrm{OH}]$ pretreatment. Commercial Avicel was used as cellulose standard to validate the results. Further, components isolated from the pretreatment condition $\left(50^{\circ} \mathrm{C}\right.$ for $\left.3 \mathrm{~h}\right)$ were utilized for cellulose crystallinity and lignin characterization studies.

Additional file 1: Fig. S1 shows the X-ray diffractograms of the untreated and pretreated switchgrass after processing at $50{ }^{\circ} \mathrm{C}$ for $3 \mathrm{~h}$. The diffractogram obtained from the untreated switchgrass has two major diffraction peaks at $22.5^{\circ}$ and $15.7^{\circ} 2 \theta$, characteristic of the cellulose I polymorph that corresponds to [002] and combined $[101]+[10 \overline{1}]$ lattice planes, respectively. The third small peak at $34.5^{\circ}$ ([040] lattice plane) corresponds to $1 / 4$ of the length of one cellobiose unit and arises from ordering along the fiber direction [38-40]. Obtained crystallinity index from the XRD patterns of the pretreated switch grass indicates that the low temperature pretreatment based on $40 \mathrm{wt} \%$ [TBA] $[\mathrm{OH}]$ has minimal impacts on cellulose. Although the diffractogram obtained from switchgrass pretreated with $[\mathrm{TBA}][\mathrm{OH}]$ still retains the cellulose I polymorph, a small shift is observed in all three peaks. The diffractogram obtained from switchgrass pretreated with $[\mathrm{TBA}][\mathrm{OH}]$ still retains the cellulose I polymorph with a realignment of [002] peak with Avicel indicating removal of amorphous cell wall components such as lignin and hemicellulose [21, 41]. This also reflected in the increase in the crystallinity index (CrI) of switchgrass from 67 to $76 \%$ after pretreatment.

\section{Sugar yields}

The sugar yields are calculated based on the glucan or xylan present in the original biomass (converting pretreated biomass to original using the solid recovery data in Table 1). As shown in Table 2, pretreatment using $[\mathrm{TBA}][\mathrm{OH}]$ at $50{ }^{\circ} \mathrm{C}$ followed by saccharification generated high glucose yields of $93.1 \%$ after $3 \mathrm{~h}$, and pretreatment at $25{ }^{\circ} \mathrm{C}$ generated glucose yields of $72.2 \%(0.5 \mathrm{~h})$ to $76.9 \%(3 \mathrm{~h})$. Not surprisingly, longer pretreatment times resulted in better glucose yields for both temperatures. Regardless of operating time, a higher xylose yield after saccharification was obtained at the lower temperatures studied, and is attributed to more hemicellulose being present in the recovered solids after pretreatment. The enhancement of sugar yields at the lower temperature aqueous $[\mathrm{TBA}][\mathrm{OH}]$ IL pretreatment is primarily due to the removal of hemicellulose and lignin. The results indicate that an aqueous solution of $40 \mathrm{wt} \%$ [TBA] [OH] solution is efficient for the pretreatment of switchgrass at mild conditions. In addition, the recyclability of [TBA] $[\mathrm{OH}]$ in biomass dissolution has been demonstrated recently [35]. Using the conditions (e.g., $50{ }^{\circ} \mathrm{C}$, vacuum degree $0.1 \mathrm{MPa}$ ), it is expected that after lignin filtration, $[\mathrm{TBA}][\mathrm{OH}]$ could be generated and reused for next run.

\section{Lignin characterization}

To examine the effect of $[\mathrm{TBA}][\mathrm{OH}]$ pretreatment process on lignin, we carried out detailed lignin characterization studies using size exclusion chromatography (SEC) and $2 \mathrm{D}^{13} \mathrm{C}-{ }^{1} \mathrm{H}$ HSQC NMR techniques. The lignin solubilized in the $[\mathrm{TBA}][\mathrm{OH}]$ after pretreatment $\left(\mathrm{L}_{1}\right)$ was

Table 1 Compositional analysis of pretreated switchgrass and the removal of the major components ${ }^{\mathrm{a}}$

\begin{tabular}{|c|c|c|c|c|c|c|c|}
\hline \multirow[t]{2}{*}{ Temp./time $\left({ }^{\circ} \mathrm{C} / \mathrm{h}\right)$} & \multirow[t]{2}{*}{ Solid recovery } & \multicolumn{3}{|c|}{ Composition of pretreated biomass } & \multicolumn{3}{|c|}{ Removal of the major components ${ }^{c}$} \\
\hline & & Glucan (\%) & Xylan (\%) & Lignin $(\%)^{\mathbf{b}}$ & Glucan (\%) & Xylan (\%) & Lignin $(\%)^{\mathbf{b}}$ \\
\hline / & / & $31.9 \pm 0.1$ & $20.2 \pm 0.1$ & $20.7 \pm 0.1$ & / & / & / \\
\hline $25 / 0.5$ & $71.3 \pm 0.5$ & $43.8 \pm 0.6$ & $19.2 \pm 0.1$ & $16.1 \pm 0.1$ & 2.2 & 32.2 & 44.7 \\
\hline $25 / 1$ & $68.5 \pm 0.5$ & $45.5 \pm 1.0$ & $18.8 \pm 0.4$ & $16.3 \pm 0.8$ & 2.3 & 36.2 & 46.2 \\
\hline $25 / 3$ & $65.2 \pm 0.4$ & $47.7 \pm 0.3$ & $18.2 \pm 0.1$ & $13.0 \pm 0.1$ & 2.4 & 41.1 & 59.0 \\
\hline $50 / 0.5$ & $57.2 \pm 0.5$ & $54.4 \pm 0.2$ & $16.6 \pm 0.2$ & $13.8 \pm 0.1$ & 2.5 & 53.0 & 62.0 \\
\hline $50 / 1$ & $51.0 \pm 0.3$ & $59.5 \pm 0.6$ & $15.9 \pm 0.3$ & $12.4 \pm 0.2$ & 4.3 & 59.8 & 69.6 \\
\hline $50 / 3$ & $48.1 \pm 0.4$ & $62.0 \pm 0.6$ & $12.7 \pm 0.1$ & $10.5 \pm 0.3$ & 6.5 & 69.8 & 75.7 \\
\hline
\end{tabular}

\footnotetext{
a The calculation is based on biomass dry weight

b Acid-insoluble lignin

c Removal of the major components is calculated based on the compositions of raw switchgrass
} 
Table 2 Glucose and xylose yields after enzymatic saccharification of the pretreated switchgrass

\begin{tabular}{llllll}
\hline Temp. $\left({ }^{\circ} \mathbf{C}\right)^{\mathbf{a}}$ & Time/h & $\begin{array}{l}\text { Glucose yield } \\
(\%)^{\mathbf{c}}\end{array}$ & SD & $\begin{array}{l}\text { Xylose yield } \\
(\%)^{\mathbf{c}}\end{array}$ & SD \\
\hline $25^{\mathrm{b}}$ & - & 15 & 2.0 & 10.0 & 2.0 \\
25 & 0.5 & 72.2 & 0.1 & 31.2 & 0.1 \\
25 & 1 & 76.2 & 0.2 & 36.4 & 0.1 \\
25 & 3 & 76.9 & 0.3 & 34.3 & 0.1 \\
50 & 0.5 & 85.6 & 0.3 & 26.4 & 0.1 \\
50 & 1 & 86.7 & 0.6 & 28.1 & 0.1 \\
50 & 3 & 93.1 & 2.54 & 20.6 & 1.34 \\
\hline
\end{tabular}

a Pretreatment temperature

b Untreated original biomass

c Calculation is based on the glucan or xylan present in the original biomass

isolated by adjusting the $\mathrm{pH}$ to $2-3$. The isolated lignin was compared with enzymatic mild acid lignin (EMAL) extracted from switchgrass, as it is commonly believed to be a close representation of the 'native' switchgrass lignin. The EMAL lignin from switchgrass was isolated based on the procedure reported by $\mathrm{Wu}$ and Argyropoulos [42]. The elution profiles acquired by monitoring UV absorbance $(\lambda=280 \mathrm{~nm})$ from SEC measurements of EMAL and the lignin isolated from the liquid stream $\left(\mathrm{L}_{1}\right)$ are depicted in Additional file 1: Fig. S2. Although the main elution peaks $\left(M_{\mathrm{w}}=1.0-10.0 \mathrm{kDa}\right)$ for both EMAL and $\mathrm{L}_{1}$ are comparable, a through comparison in the higher molecular weight region $\left(M_{\mathrm{w}}>10.0 \mathrm{kDa}\right)$ region shows that $\mathrm{L}_{1}$ has slightly lower molecular weight than EMAL, indicating small reduction of size. Apart from that $\mathrm{L}_{1}$ shows greater low molecular weight tails $\left(M_{\mathrm{w}}>1.0 \mathrm{kDa}\right)$ along with one new intense low molecular weight peak $\left(M_{\mathrm{w}}=322 \mathrm{Da}\right)$, both these observations indicate more abundant lower molecular weight lignin fractions as compared to EMAL.

To understand the structural changes that occur in lignin during the pretreatment process, the isolated lignin was compared with EMAL and raw switchgrass using 2D ${ }^{13} \mathrm{C}-{ }^{1} \mathrm{H}$ heteronuclear single quantum coherence (HSQC) nuclear magnetic resonance (NMR) (Fig. 2). The cross peaks were assigned according to standards reported in the literature [43-49]. The structures in these HSQC spectra correspond to the color-coded structures depicted in Additional file 1: Fig. S3. Lignin side chains and interunit correlations are shown in aliphatic (top row, Fig. 2a) and aromatic regions (bottom row, Fig. 2c) and the polysaccharides are shown in the anomeric region (middle row, Fig. 2b). The relative changes in the lignin chemical structures were determined based on the volume integrations of HSQC spectral contour correlations. The HSQC spectrum of the cell wall of the untreated switchgrass shows that the $\beta$-aryl ether interunit linkages $\left(A_{\alpha}, A_{\beta(H / G)}, A_{\beta(S)}\right.$, substructure $\left.A\right)$ are the predominant linkages in the lignin with small contributions of phenylcoumaran $(\beta-5$, substructure $B)$, resinol $(\beta-\beta$, substructure $C$ ), and dibenzodioxocin (substructure $D$ ) linkages. The aliphatic region also exhibits two distinct peaks of 2-O-Ac- $\beta$-D-Xyl $p(\mathrm{R})\left(\mathrm{X}_{2}\right)$ and 3-O-Ac- $\beta$-D-Xyl $p(\mathrm{R})\left(\mathrm{X}_{3}\right)$ that represent major acetylated components of hemicelluloses. The aromatic region of the cell wall of the raw switchgrass indicates that the lignin is a S/G type lignin with a minor amount of $\mathrm{H}$-type lignin containing $p$-coumarates ( $p \mathrm{CA})$ and ferulates (FA), which is consistent with previous literature reports $[43,46,47,49]$. The HSQC spectrum of the untreated switchgrass also shows the presence of tricin moieties (substructure $\mathrm{T}$ ).

The HSQC spectrum of $L_{1}$ is shown in Fig. $2 g-i$. The weaker signal intensity of the $A_{\alpha}$ interunit linkages suggest chemical changes in the $\beta$-aryl ethers during the $[\mathrm{TBA}][\mathrm{OH}]$ pretreatment. The absence of dibenzodioxocin signal $(\delta \mathrm{C} / \delta \mathrm{H}: 83.3 / 4.81 \mathrm{ppm})$ indicates that the lignin isolated from the liquid stream is more linear as compared to the branched lignin in the untreated switchgrass due to removal of the points of branching [50]. Additionally, the absence of $\mathrm{X} 2{ }_{2}$ and $\mathrm{X} 3_{3}$ correlations suggest deacetylation of hemicellulose occurred more readily at $\mathrm{C}_{2} / \mathrm{H}_{2}$ position. The anomeric regions of the untreated biomass and $\mathrm{L}_{1}$ demonstrates a noticeable decrease of $\alpha-\mathrm{D}-\mathrm{Glcp}(\mathrm{R}) / \alpha-\mathrm{D}-\mathrm{Xlyp}(\mathrm{R})$, may be due to glycosidic bond cleavage and reduction in the degree of polymerization (DP) of hemicellulose during $[\mathrm{TBA}][\mathrm{OH}]$ pretreatment. When compared with the switchgrass EMAL (Fig. 2d-f), $\mathrm{L}_{1}$ has similar interunit traits in both aliphatic and aromatic regions of the HSQC spectra. The relative abundance of different interunit linkages in EMAL and $\mathrm{L}_{1}$ is shown in Additional file 1: Fig. S4. In $\mathrm{L}_{1}$, the $\beta$-aryl ether interunit linkages decrease from 59 to $43 \%$ as compared to the EMAL, with a relatively smaller decrease in both phenylcoumaran and resinol substructures. This result is in agreement with the SEC results, confirming reduction of the lignin size due to depolymerization during [TBA] $[\mathrm{OH}]$ pretreatment process. The absence of detectable dibenzodioxocin substructure suggests relatively linear lignin structure of both types of lignins. Tricin substructures were also detected in both EMAL and $\mathrm{L}_{1}$ [51]. The SEC and 2D NMR studies suggested that $\mathrm{L}_{1}$ has similar structure traits as switchgrass EMAL with a relatively smaller size. These results indicate that $[\mathrm{TBA}][\mathrm{OH}]$ can very efficiently solubilize and partially depolymerize the lignin present in switchgrass.

\section{Glycome profiling}

Glycome profiling of untreated and $[\mathrm{TBA}][\mathrm{OH}]$ pretreated switchgrass biomass was conducted to facilitate a 


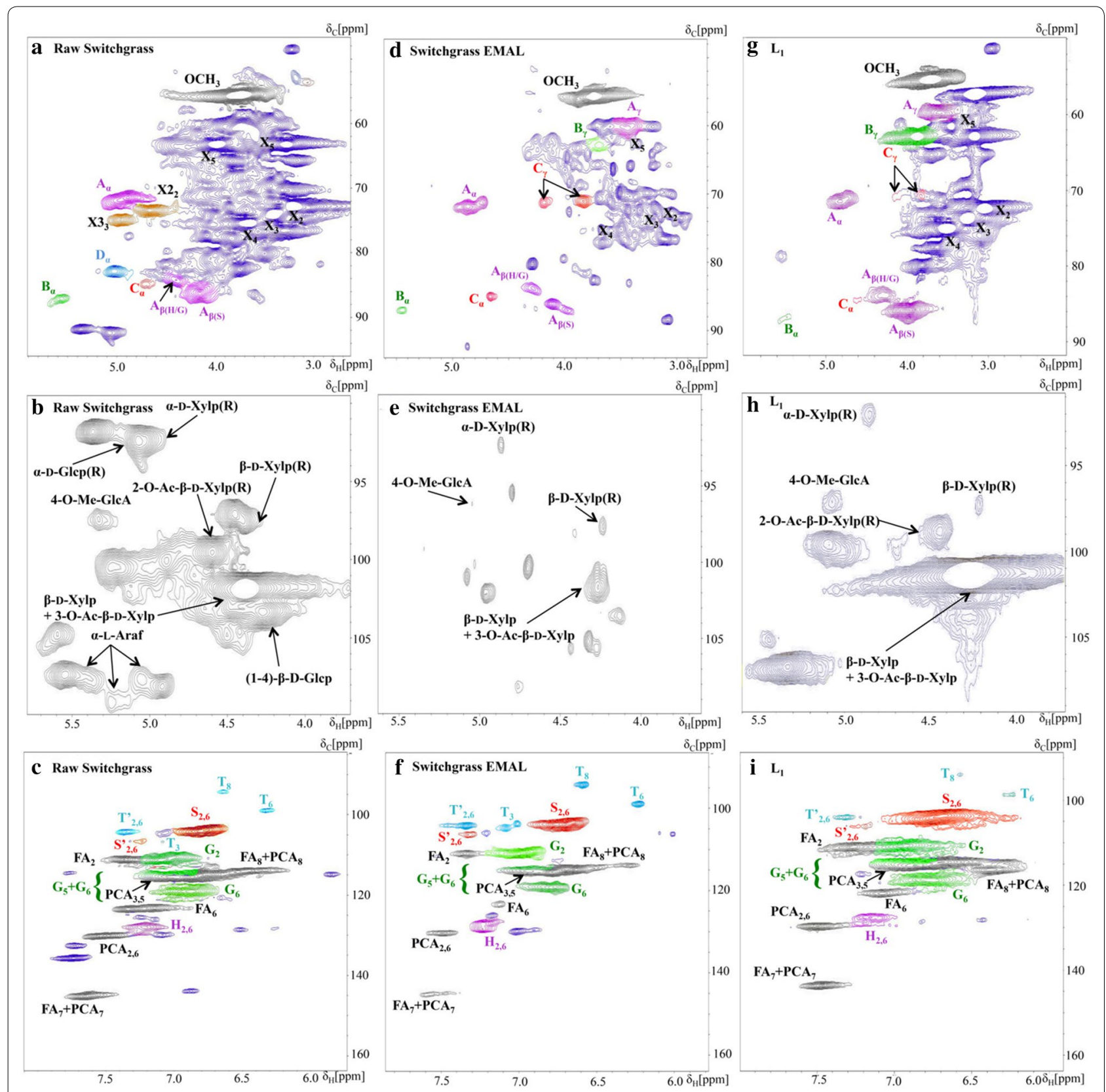

Fig. 2 2D HSQC NMR spectra of aliphatic regions of untreated switchgrass (a), EMAL (d) and $\mathrm{L}_{1}(\mathbf{g})$; anomeric regions of untreated switchgrass (b), $\operatorname{EMAL}(\mathbf{e})$ and $\mathrm{L}_{1}(\mathbf{h})$; and aromatic regions of untreated switchgrass $(\mathbf{c}), \operatorname{EMAL}(\mathbf{f})$ and $\mathrm{L}_{1}(\mathbf{i})$

comparative study of the overall changes in composition and extractability patterns of the major noncellulosic cell wall glycans. Concomitantly, the results from glycome profiling analyses were employed to understand how $[\mathrm{TBA}][\mathrm{OH}]$ pretreatment cause reduced cell wall recalcitrance in switchgrass. Glycome profiles of untreated and $[\mathrm{TBA}][\mathrm{OH}]$ pretreated switchgrass at $50{ }^{\circ} \mathrm{C}$, as depicted in Fig. 3, revealed significant differences that are highlighted in the yellow dotted blocks. These significant differences in the glycome profiles of pretreated biomass indicate that pretreatment regime caused an overall change in cell wall structure, architecture and composition. In general, $[\mathrm{TBA}][\mathrm{OH}]$ pretreated switchgrass exhibited lesser amounts of materials recovered (see bar graphs on top panel) in all base extracts $(1 \mathrm{M} \mathrm{KOH}, 4 \mathrm{M}$ $\mathrm{KOH}$ and $4 \mathrm{M} \mathrm{KOHPC)} \mathrm{hinting} \mathrm{at} \mathrm{the} \mathrm{removal} \mathrm{and} \mathrm{frag-}$ mentation of potentially noncellulosic cell wall components (that may also include hemicelluloses) during the 


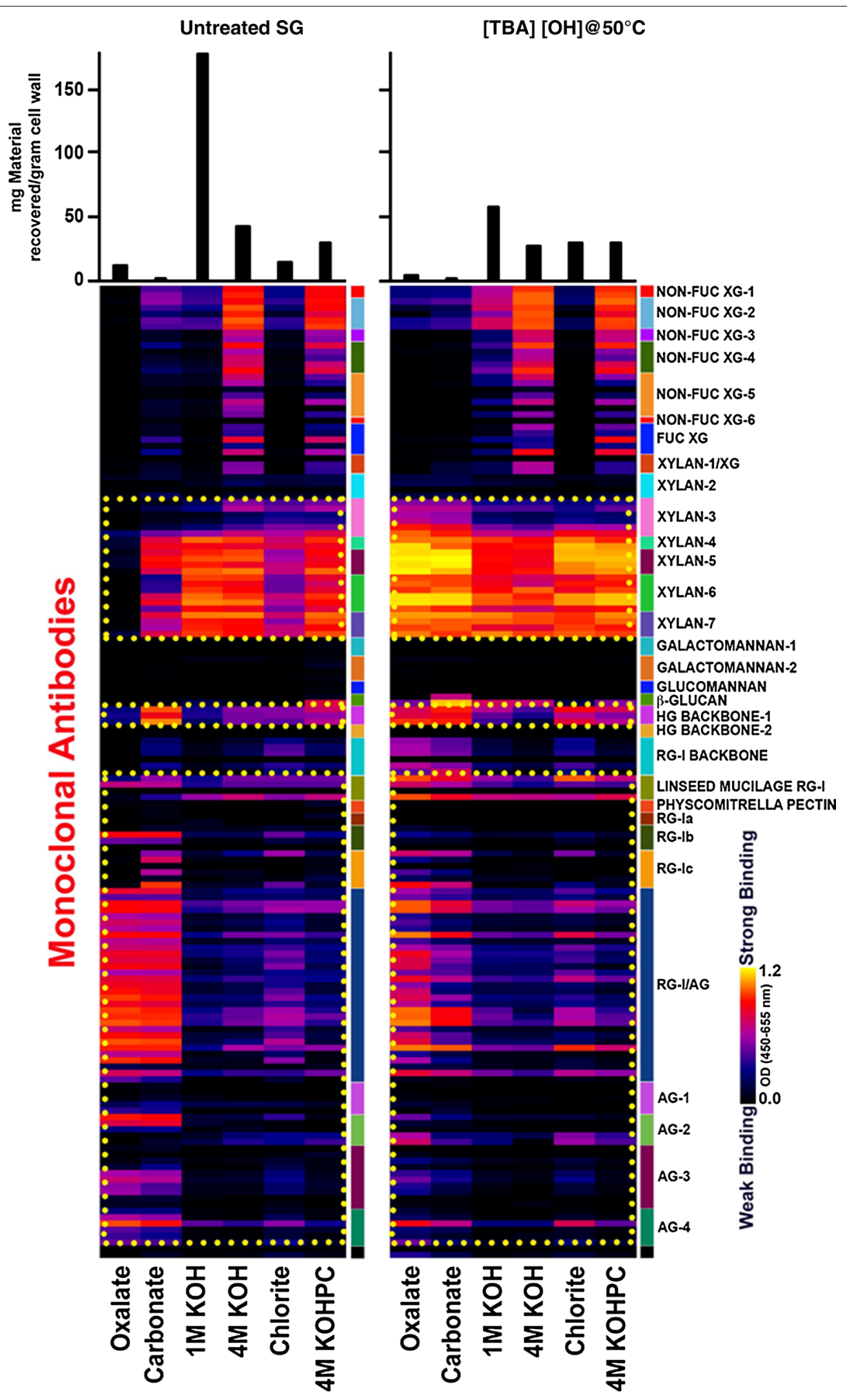

Fig. 3 Glycome profiling of untreated switchgrass, and switchgrass pretreated with $[\mathrm{TBA}][\mathrm{OH}]$ at $50^{\circ} \mathrm{C}$ for $3 \mathrm{~h}$ : Sequential cell wall extracts (bottom) were subjected to ELISA screens with monoclonal antibodies for most major noncellulosic plant glycan classes (right). The ELISA binding response values are represented as a color-coded "heatmap" (center) and the recovered masses of carbohydrate material resulting from each extraction step is represented with bar graphs (top) 
[TBA] $[\mathrm{OH}]$ pretreatment process. Interestingly, prominent variations were observed in the abundances of noncellulosic glycan epitopes in oxalate and carbonate extracts from pretreated biomass samples in comparison to the untreated biomass. For instance, a considerably higher abundance of xylan epitopes (as indicated by the higher binding of xylan-3 through xylan-7 groups of $m$ Abs that recognize both unsubstituted and substituted xylans) was observed in oxalate and carbonate extracts from $[\mathrm{TBA}][\mathrm{OH}]$ pretreated switchgrass at $50{ }^{\circ} \mathrm{C}$ that indicates enhanced xylan extractability. As previous studies have noted, such enhanced extractability of xylan epitopes is indicative of structural changes in the cell walls that results in reduced recalcitrance [52].

Substantial differences in patterns of extractabilities of epitopes of pectic components were also observed between the untreated and [TBA] $[\mathrm{OH}]$ pretreated switchgrass. For example, oxalate extracts from $[\mathrm{TBA}][\mathrm{OH}]$ pretreated samples showed significantly higher abundance of pectic backbone epitopes (as indicated by the higher binding of homogalacturonan backbone-1 and rhamnogalacturonan-I backbone groups of mAbs). Pectic arabinogalactan and arabinogalactan epitopes (as indicated by the binding of RG-I/AG and AG groups of mAbs) were highly abundant in oxalate and carbonate extracts from untreated switchgrass, however, this abundance decreased in $[\mathrm{TBA}][\mathrm{OH}]$ pretreated switchgrass samples (potentially due to enhanced glycan fragmentation). The chlorite extraction step employed in sequential extraction breaks up and removes lignin to release any lignin-associated polysaccharides into the extract. Chlorite extracts from pretreated switchgrass under $[\mathrm{TBA}][\mathrm{OH}]$ at $50{ }^{\circ} \mathrm{C}$ conditions contained higher abundance of xylan epitopes as compared to untreated samples indicating ILs perturbing effect on potential lignin-xylan associations. Overall, glycome profiling studies revealed the major structural modifications induced by $[\mathrm{TBA}][\mathrm{OH}]$ at the mild pretreatment condition on switchgrass biomass resulting in efficient hydrolysis of cellulose to its constituent sugars.

\section{Computational modeling}

To understand the molecular level forces on the biomass dissolution at low temperature using $[\mathrm{TBA}][\mathrm{OH}]$, the first requirement is to determine the chemical nature of $[\mathrm{TBA}][\mathrm{OH}]$ that solubilizes lignocellulose. The optimized molecular geometry of [TBA] $[\mathrm{OH}]$ obtained using hybrid density functional theory (DFT) calculations is shown in Fig. 4. The most stable conformation arises from interactions of an oxygen atom of the $[\mathrm{OH}]^{-}$with the ionic region around nitrogen atom in $[\mathrm{TBA}]^{+}$. Due to the short $\mathrm{O}_{\mathrm{OH}} \ldots \mathrm{H}_{-} \mathrm{C}_{\mathrm{TBA}}$ bond distances (1.91-1.97 $\AA$ ) between cation and the anion of $[\mathrm{TBA}][\mathrm{OH}]$ allowing strong intermolecular interaction energy (IE) $(116.8 \mathrm{kcal} / \mathrm{mol})$ of those ion pairs. It is clearly seen from the depicted molecular electrostatic potential (MESP) map of [TBA] $[\mathrm{OH}]$ that the distinct separation of positive (blue) and negative regions (red) play a dominant role by influencing strong ionic interactions, electrostatics, and hydrophobic interactions with biomass components [53].

We evaluated the influence of the anion and cation interactions on biomass dissolution by performing quantum chemical calculations of $\left.[\mathrm{OH}]^{-},{ }^{\mathrm{TBA}}\right]^{+}$and $[\mathrm{TBA}][\mathrm{OH}]$ interacting with a model dilignol and cellobiose compounds (Fig. 5). From the calculated IEs, it was found that $[\mathrm{OH}]^{-}$interacts with dilignol and cellobiose more strongly than $[\mathrm{TBA}]^{+}$cation, and the $\mathrm{IE}$ of $[\mathrm{OH}]^{-}$with cellobiose is slightly higher than that of its interactions with dilignol. In the case of $[\mathrm{TBA}]^{+}$interactions, our calculations show a slightly higher IE for cellobiose than for dilignol, which are most probably due to hydrophobic interactions. Interestingly, IE strength of ion pair complexes with biomass components are more favored toward dilignol than cellobiose. This trend agrees with the experimental observation on lignin removal and provides insights on $[\mathrm{TBA}][\mathrm{OH}]$ interactions with biomass components. Previous experimental studies [35] on [TBA] $[\mathrm{OH}]$ that have been carried out on cellulose show strong contact with cellulose in the absence of any other competing biomass compounds (i.e., lignin). Considering the components in whole biomass, interactions with $[\mathrm{TBA}][\mathrm{OH}]$ reveal that this IL has more affinity with lignin, and thus enables higher amount of lignin removal. Delignification of $[\mathrm{TBA}][\mathrm{OH}]$ enhances the cellulose accessibility for enzymatic digestion. Another important point to note is that $[\mathrm{TBA}][\mathrm{OH}]$ interactions could also account for biomass permeability as a result of the large amount of xylan removal by the $[\mathrm{OH}]^{-}$, since these types of bases are known to involve reactions under mild conditions [7]. It has been reported that alkaline ions could instigate the progression of following steps involving (i) cellulose swelling; (ii) internal surface area enhancement; (iii) changes in cellulose crystallinity; (iv) hemicellulose removal; (v) reducing the lignin and carbohydrate association; and (vi) disrupting the lignin structure by breaking its glycosidic ether bond. Hence, lignin cannot further act as a protective shield to the cellulose after lignin dissolution, consequently making cellulose more susceptible for degradation.

We then sought to determine what properties and interactions are dominant at these lower temperatures. Ionic conductivity, ion mobility, and viscosity of ILs are the key factors and vary based on ion type, size, charge, and temperature [54]. The higher $\mathrm{pH}(\sim 14)$ of [TBA] [OH] significantly influences the lignin removal [55]. The low temperature mechanism of biomass dissolution is particularly dependent on the ion exchange and contribution from ionic interactions between the biomass and ILs. Optimized geometries of lignin with $\left[\mathrm{C}_{2} \mathrm{C}_{1} \mathrm{Im}\right][\mathrm{OAc}]$ 

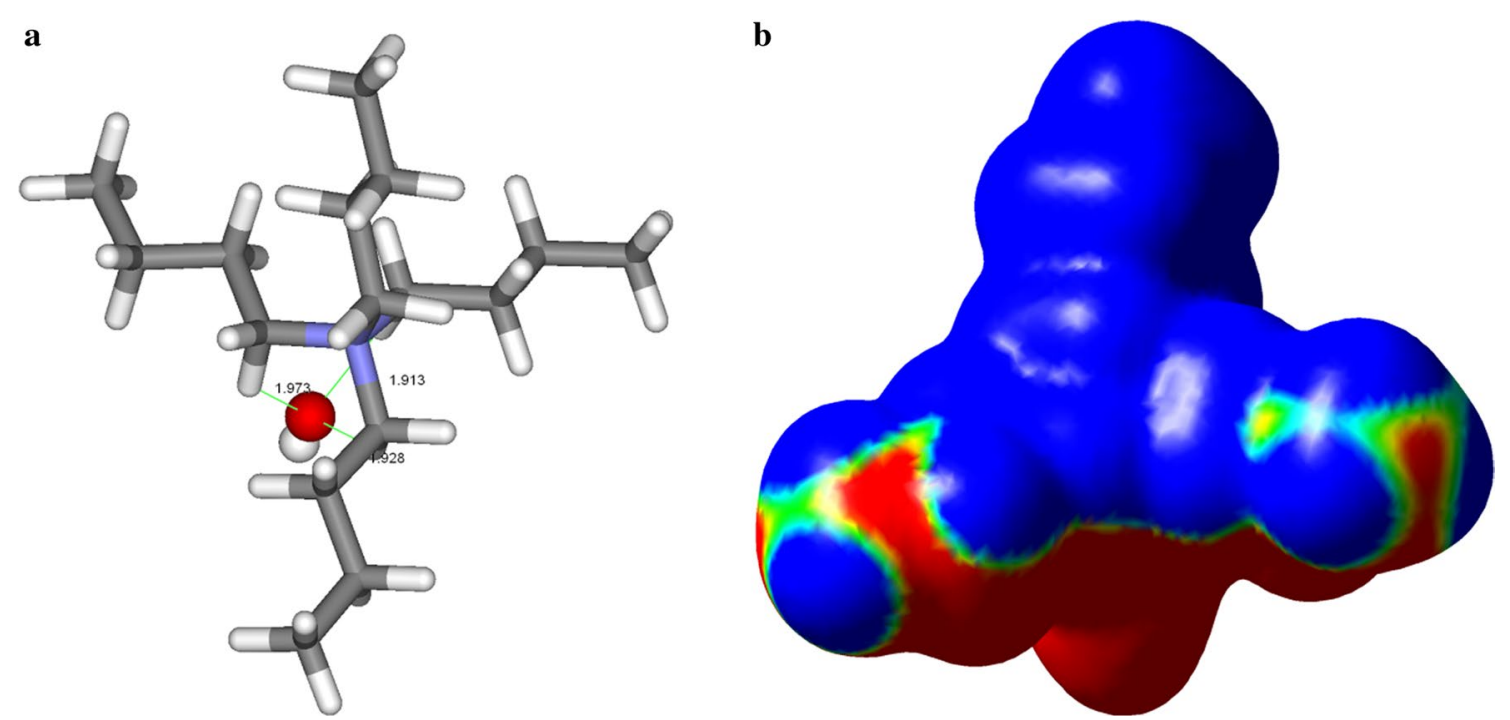

Fig. 4 a Optimized geometry indicating anion cation association $\mathbf{b}$ molecular electrostatic potential map of [TBA][OH] at the \pm 0.04 au isosurface. The color scale indicates the charges on the atoms: red = most negative, green = neutral, blue = most positive charge

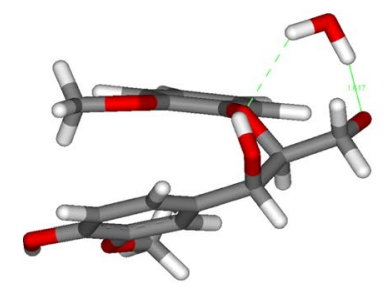

Dilignol-[OH]', IE=137.6

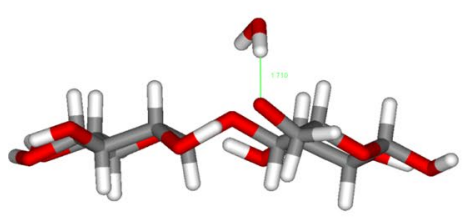

Cellobiose- $[\mathrm{OH}]^{-}, \mathrm{IE}=169.4$

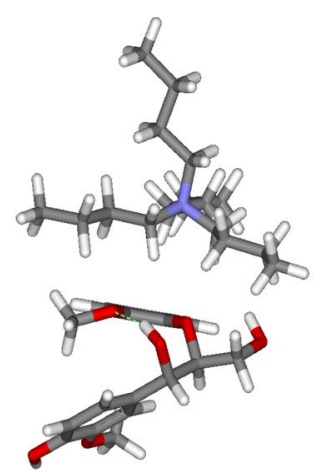

Dilignol-[TBA] $]^{+}, \mathrm{IE}=16.8$

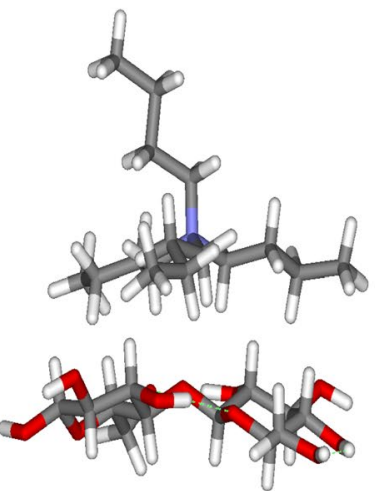

Cellobiose-[TBA], $\mathrm{IE}=19.8$

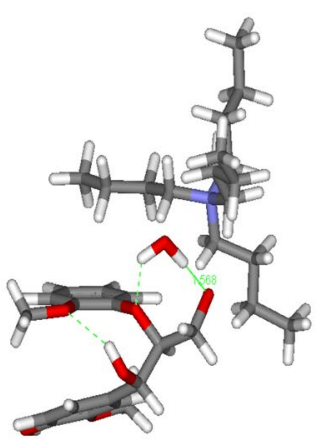

Dilignol-

[[TBA $][\mathrm{OH}]], \mathrm{IE}=125.9$

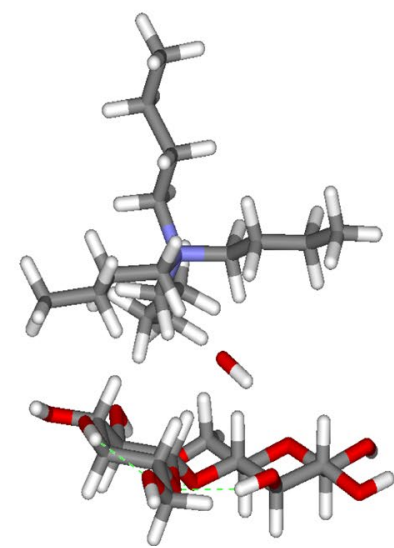

Cellobiose-[[TBA][OH]], $\mathrm{IE}=116.8$

Fig. 5 Optimized geometries of dilignol and cellobiose with $[\mathrm{OH}]^{-},[\mathrm{TBA}]^{+}$and $[\mathrm{TBA}][\mathrm{OH}]$. Interaction energy (IE) is reported in kcal/mol 
and lignin with [TBA] [OH] (Additional file 1: Fig. S5) are analyzed more carefully. It is interesting to point out that the proton/hydrogen exchange from the dilignol to $[\mathrm{OH}]$ anion has seen for the [TBA][OH]-lignin complexes. On the other hand, no significant elongation was observed for the $\mathrm{O}-\mathrm{H}$ group of the lignin interacting with $[\mathrm{OAc}]^{-}$ of $\left[\mathrm{C}_{2} \mathrm{C}_{1} \mathrm{Im}\right][\mathrm{OAc}]$-lignin complexes. This ion mobility of $[\mathrm{OH}]^{-}$enhances the ionic conductivity, and the $\left[\mathrm{C}_{2} \mathrm{C}_{1} \mathrm{Im}\right]^{+}$ is involved in stabilizing the complexes. Therefore, [TBA] $[\mathrm{OH}]$ is more reactive than the other ILs used in pretreatment at higher temperature in terms of ionic interactions that extends their solvation capability at the lower temperature. Higher temperature conditions could manipulate these solvation properties for other ILs with different anions and cations. More importantly, ion pair type, size, charge, and co-solvents can be modified to design ILs with effective ionic conductivity and viscosity [56] for the efficient biomass dissolution under mild conditions.

\section{Process modeling and energy demand analysis on low temperature IL pretreatment}

One important consideration for the developed pretreatment for $[\mathrm{TBA}][\mathrm{OH}]$ is lower temperature process. To understand the impact of $[\mathrm{TBA}][\mathrm{OH}]$ based low temperature pretreatment demonstrated in this study on the energy requirement, a process model was developed in SuperPro Designer (v8.5). The process consists of a pretreatment reactor and the performance of [TBA] $[\mathrm{OH}]$ pretreatment process, in terms of energy intensity, is benchmarked against a more conventional $\left[\mathrm{C}_{2} \mathrm{C}_{1} \mathrm{Im}\right]$ [OAc] process. The $[\mathrm{TBA}][\mathrm{OH}]$ pretreatment was carried out at $50{ }^{\circ} \mathrm{C}$ while the $\left[\mathrm{C}_{2} \mathrm{C}_{1} \mathrm{Im}\right][\mathrm{OAc}]$ pretreatment was conducted at $160{ }^{\circ} \mathrm{C}$. Physical properties of the ILs (such as heat capacity) were collected from the literature [57]. Overall, four scenarios were constructed using these two ILs and two different biomass loadings (i.e., 10 and $20 \%$ ). Energy demand calculations revealed more than $75 \%$ reduction in steam requirement during the low temperature pretreatment process to liberate carbohydrates with reduced energy input (Fig. 6) [36]. As shown in the Fig. 6, the impact of pretreatment temperature on energy requirement is lower for $[\mathrm{TBA}][\mathrm{OH}]$ in both biomass loading conditions compared to $\left[\mathrm{C}_{2} \mathrm{C}_{1} \mathrm{Im}\right][\mathrm{OAc}]$. This effort could potentially address the challenging issues of developing robust and energy efficient technologies for increasing the sugar yields at a lower cost from renewable, nonfood lignocellulosic biomass.

\section{Conclusions}

We have demonstrated the low temperature pretreatment of lignocellulosic biomass using the IL $[\mathrm{TBA}][\mathrm{OH}]$ in the presence of water. The concept of inducing labile biomass deconstruction with reduced energy input and minimal IL

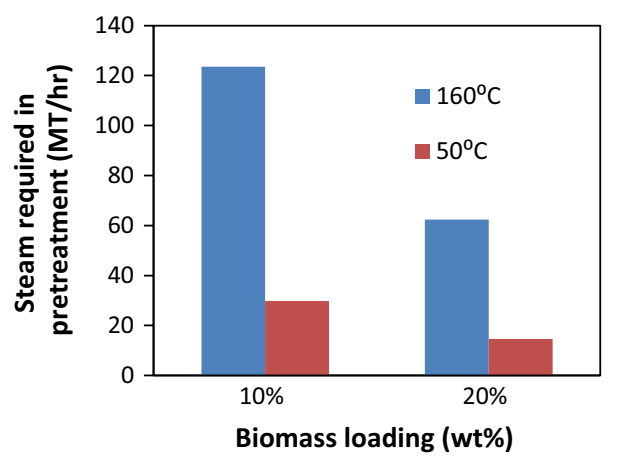

Fig. 6 Impact of the temperature on energy requirement in the pretreatment process at industrial scale (to process 2000 MT/day dry biomass)

loading has been successfully demonstrated. The effective pretreatment of $10 \mathrm{wt} \%$ switchgrass using aqueous mixtures of $[\mathrm{TBA}][\mathrm{OH}]$ at $50{ }^{\circ} \mathrm{C}$ generated $>90 \%$ glucose yields and outperformed current best IL pretreatment based on imidazolium ILs at similar severities. Process modeling and energy demand analysis has shown significant potential for reduction in the pretreatment energy requirement. For instance, this results in more than a $75 \%$ reduction in the steam requirement for $[\mathrm{TBA}][\mathrm{OH}]$ compared to ILs that are used at temperatures above $140{ }^{\circ} \mathrm{C}$. Compositional analysis of the $[\mathrm{TBA}][\mathrm{OH}]$ pretreated switchgrass show that the enhancement of sugar yields at lower temperatures is due to the removal of hemicellulose and lignin. Lignin characterization using SEC and NMR on the extracted lignin after pretreatment indicates that $[\mathrm{TBA}][\mathrm{OH}]$ efficiently solubilizes and partially depolymerizes the lignin during pretreatment. DFT computations on chemical reactivity of $[\mathrm{TBA}][\mathrm{OH}]$ and its interaction with cellobiose and lignin reveal that $[\mathrm{TBA}][\mathrm{OH}] \mathrm{IL}$ is more reactive than the imidazolium IL used in pretreatment at higher temperature in terms of ionic mobility which enables lignin removal at the lower temperature. Glycome profiling experiments provide evidence for significant removal of noncellulosic components of biomass under mild $[\mathrm{TBA}][\mathrm{OH}]$ pretreatment that is distinct from other ILs that require a higher temperature for better performance. By leveraging the benefits of ILs that are effective at very mild processing conditions, such as $[\mathrm{TBA}][\mathrm{OH}]$, this study opens up an avenue for novel process designs that could significantly enhance the energy efficiency and affordability of the biorefinery by overcoming the temperature mismatch of pretreatment and saccharification unit operations.

\section{Methods}

\section{Materials}

Switchgrass (Panicum virgatum) was kindly provided from the laboratory of Prof. Daniel Putnam at the 
University of California, Davis. The switchgrass studied was a combination of lowland and upland varieties, grown in Davis, California and harvested in 2011. The samples were ground using a Thomas-Wiley ${ }^{\circledR}$ Mill fitted with a 20-mesh screen (Model 3383-L10 Arthur H. Thomas Co., Philadelphia, PA, USA) and used without further sieving. The samples were stored at $4{ }^{\circ} \mathrm{C}$ in a sealed plastic bag for use in all experiments. Commercial enzyme cocktails Cellic ${ }^{\circledR}$ CTec 2 and HTec 2 were generously provided by Novozymes (Davis, CA). The ILs [TBA][OH] (>95\% purity) were purchased from Sigma-Aldrich.

\section{Biomass pretreatment}

A $10 \%(\mathrm{w} / \mathrm{w})$ biomass solution was prepared by combining $1 \mathrm{~g}$ of switchgrass with $9 \mathrm{~g}$ of IL in a $25 \mathrm{~mL}$ tube reactor. The reactor was heated in an oil bath to the desired temperature and stirred at $150 \mathrm{rpm}$ with a magnetic stir bar for $3 \mathrm{~h}$. All pretreatment reactions were conducted in duplicate. Following pretreatment, $30 \mathrm{~mL}$ of deionized (DI) water was slowly added to the biomass/IL slurry with continued stirring. The mixture was transferred to $25 \mathrm{~mL}$ Falcon tubes and centrifuged at high speed $(14,000 \mathrm{rpm})$ to separate solids. The pretreated biomass was further washed with $4 \times 30 \mathrm{~mL}$ of DI water to remove any residual IL. The solids were lyophilized and stored at $4{ }^{\circ} \mathrm{C}$ for analysis.

\section{Compositional analysis}

Compositional analysis of switchgrass before and after pretreatment was performed using NREL acidolysis protocols (LAP) LAP-002 and LAP-005. Briefly, $200 \mathrm{mg}$ of biomass and $2 \mathrm{~mL} 72 \% \mathrm{H}_{2} \mathrm{SO}_{4}$ were incubated at $30{ }^{\circ} \mathrm{C}$ while shaking at $300 \mathrm{rpm}$ for $1 \mathrm{~h}$. The solution was diluted to $4 \% \mathrm{H}_{2} \mathrm{SO}_{4}$ with $56 \mathrm{~mL}$ of DI water and autoclaved for $1 \mathrm{~h}$ at $121{ }^{\circ} \mathrm{C}$. The reaction was quenched by placing samples into an ice bath before removing the biomass by filtration. The filtrate was neutralized with $\mathrm{CaCO}_{3}$ and monomeric sugars were determined from the filtrate by Agilent HPLC 1200 Series equipped with a Bio-Rad Aminex HPX-87P column and a refractive index detector (aqueous mobile phase, $0.6 \mathrm{~mL} / \mathrm{min}$, column temperature $85^{\circ} \mathrm{C}$ ). The injection volume was $10 \mu \mathrm{L}$ with a run time of $25 \mathrm{~min}$. Acid-insoluble lignin was quantified gravimetrically from the solid after heating overnight at $105^{\circ} \mathrm{C}$ (the weight of acid-insoluble lignin + ash) and then $575^{\circ} \mathrm{C}$ for at least $6 \mathrm{~h}$ (the weight of ash).

\section{Enzymatic saccharification}

Enzymatic saccharification of pretreated and untreated biomass was carried out using commercially available enzymes, Cellic ${ }^{\circledR} \mathrm{CTec} 2$ and $\mathrm{HTec} 2$ from Novozymes, at $50{ }^{\circ} \mathrm{C}, \mathrm{pH} 5.5$, and rotation speed of $150 \mathrm{rpm}$ in a rotary incubator (Enviro-Genie, Scientific Industries, Inc.). All reactions were conducted at $10 \%$ biomass loading by placing $500 \mathrm{mg}$ of biomass (dry weight) in a $25 \mathrm{~mL}$ centrifuge tube. The $\mathrm{pH}$ of the mixture was adjusted to 5.5 with $50 \mathrm{mM}$ sodium citrate buffer ( $\mathrm{pH} 4.8$ ) supplemented with $0.02 \% \mathrm{NaN} 3$ to prevent microbial contamination. The total reaction volume $(5 \mathrm{~mL})$ included a total protein content of $10 \mathrm{mg}$ protein/g biomass (before pretreatment). The ratio of CTec2:HTec2 mixtures were held constant at 9:1 for all reactions. Reactions were monitored by centrifuging $50 \mu \mathrm{L}$ aliquots of supernatant ( $5 \mathrm{~min}, 14,000 \mathrm{rpm}$ ) at specific time intervals and measuring monomeric sugar concentrations by HPLC as described previously.

\section{X-ray diffraction (XRD)}

The raw and pretreated biomass/Avicel were dried and characterized with powder X-ray diffraction (PXRD). The XRD analysis were performed on a PANalytical Empyrean X-ray diffractometer equipped with a PIXcel ${ }^{3 \mathrm{D}}$ detector and operated at $45 \mathrm{kV}$ and $40 \mathrm{kA}$ using $\mathrm{Cu} \mathrm{K \alpha}$ radiation $(\lambda=1.5418 \AA)$. The patterns are collected in the $2 \theta$ range from $5^{\circ}$ to $60^{\circ}$ with a step size of $0.039^{\circ}$ and the exposure time of $300 \mathrm{~s}$. A reflection-transmission spinner was used as a sample holder and the spinning rate was set at $8 \mathrm{rpm}$ throughout the experiment. Crystallinity index (CrI) was determined by Segal's method [58].

\section{$2 D^{13} \mathrm{C}-{ }^{1} \mathrm{H}$ HSQC NMR spectroscopy}

Switchgrass cell wall and solids recovered from the liquid stream $[\mathrm{TBA}][\mathrm{OH}]$ IL pretreatment via adjusting the $\mathrm{pH}$ were ball-milled, solubilized in DMSO- $d 6$, and then analyzed by two-dimensional (2D) ${ }^{13} \mathrm{C}-{ }^{1} \mathrm{H}$ heteronuclear single quantum coherence (HSQC) nuclear magnetic resonance (NMR) as previously described [46]. Briefly, ball-milled samples $(\sim 50 \mathrm{mg})$ were placed in NMR tubes with $600 \mu \mathrm{l}$ DMSO-d6. The samples were sealed and sonicated until homogeneous in a Branson 2510 table-top cleaner Branson Ultrasonic Corporation, Danburt, CT). The temperature of the bath was closely monitored and maintained below $50{ }^{\circ} \mathrm{C}$. HSQC spectra were acquired at $398 \mathrm{~K}$ using a Bruker Avance- $600 \mathrm{MHz}$ instrument equipped with a $5 \mathrm{~mm}$ inverse gradient ${ }^{1} \mathrm{H} /{ }^{13} \mathrm{C}$ cryoprobe using the q_hsqcetgp pulse program $(\mathrm{ns}=64, \mathrm{ds}=16$, number of increments $=256, \mathrm{~d} 1=1.5 \mathrm{~s}$ ). Chemical shifts were referenced to the central DMSO peak $(\delta \mathrm{C} / \delta \mathrm{H}$ $39.5 / 2.5 \mathrm{ppm})$. Assignment of the HSQC spectra is described elsewhere. A semi-quantitative analysis of the volume integrals of the HSQC correlation peaks was performed using Bruker's Topspin 3.1 processing software.

\section{Size exclusion chromatography (SEC)}

The molecular weight distribution of lignin was investigated using a gel permeation chromatography (GPC). 
The lignin was acetylated with pyridine and acetic anhydride following a previously published procedure [59]. The acetylated lignin was dissolved in tetrahydrofuran (THF) with a concentration of $1 \mathrm{~g} / \mathrm{L}$. GPC analysis was performed using a Tosoh Ecosec HLC-8320 GPC equipped with a refractive index (RI) and diode array detector (DAD) detector. Separation was achieved with an Agilent PLgel $5 \mu \mathrm{m}$ Mixed-D column at $35{ }^{\circ} \mathrm{C}$ using a mobile phase of THF at a flow rate of $1.0 \mathrm{~mL} / \mathrm{min}$. The GPC standards, which contained polystyrene ranging from 162 to 29,150 g/mol, were purchased from Agilent and used for calibration. Absorbance of materials eluting from the column was detected at $280 \mathrm{~nm}$ (UV). The enzymatic mild acidolysis lignin (EMAL) process was used to extract lignin from switchgrass and it was used as a control.

\section{Computational details}

The geometry optimizations of [TBA] cations and hydroxide anions, cellobiose, lignin dimer model (dilignol with $\beta-O-4$ linkage between two arene rings) were performed using density functional theory (DFT) with the M06-2X hybrid exchange-correlation functional and the 6-311 ++G(d, p) basis set. Frequency calculations were carried out to verify that the computed structures corresponded to energy minima. The most stable isolated cation/anion and their IL complexes obtained from our calculations are herein described. Several complexes of anions and cations interacting with cellobiose and dilignol (guided by the electrostatic potentials) were constructed and optimized at M06-2X/6-31G (d, p) basis set. The most stable complexes of cation and anion with cellobiose and dilignol were used to calculate interaction energies (IEs) at M06-2X/6-311 ++G(d, p) level using the supermolecular approach,

$$
\mathrm{IE}=-\left(E_{\text {Complex }}-\sum_{i=1}^{n} E_{i}\right)
$$

where $E_{\text {Complex }}$ refer to the energies of cation and anion pair (for IL), anion or cation with biomass components, anion and cation with biomass complexes, respectively, and $E_{\mathrm{i}}$ refer to the energies of monomers. The results were corrected for basis set superposition error (BSSE) following the procedure adopted by Boys and Bernardi [60]. All quantum chemical calculations were performed using the Gaussian 09 suite of programs [Frisch et al. (2009) Gaussian 09 (Gaussian, Inc, Wallingford, CT), Revision D.01.] [61].

\section{Glycome profiling}

Glycome profiling of raw and [TBA][OH] IL pretreated biomass samples that involves preparation of cell walls
[Alcohol Insoluble Residues (AIR)], sequential extractions of AIR were carried out as previously described $[62,63]$. Plant cell wall glycan-directed monoclonal antibodies (mAbs) were from laboratory stocks (CCRC, JIM and MAC series) at the Complex Carbohydrate Research Center (available through CarboSource Services; http:// www.carbosource.net) or were obtained from BioSupplies (Australia) (BG1, LAMP). Supporting information on mAbs [64] used in this study can be found in the Supplementary Information Table S1, including the link to WallMabDB (http://www.wallmabdb.net) that provides detailed information for each antibody.

\section{Additional file}

Additional file 1: Supporting Table S1: Detailed list of cell wall glycandirected monoclonal antibodies (mAbs) used for glycome profiling analyses. The groupings of antibodies are based on a hierarchical clustering of ELISA data generated from a screen of all mAbs against a comprehensive panel of plant polysaccharide preparations that clusters mAbs according to the predominant polysaccharides that they recognize. The majority of listings link to the WallMabDB plant cell wall monoclonal antibody database (http://www.wallmabdb.net) that provides detailed descriptions of each $\mathrm{mAb}$, including immunogen, antibody isotype, epitope structure (to the extent known), supplier information, and related literature citations. Figure S1. X-ray diffraction patterns and $\mathrm{Crl}(\%)$ values of untreated Avicel, switchgrass solids and pretreated switch grass by $[\mathrm{TBA}][\mathrm{OH}]$ at $50^{\circ} \mathrm{C}$ pretreatment conditions. Figure S2. Normalized SEC chromatograms of EMAL- switchgrass and $\mathrm{L}_{1}$. Figure $\mathbf{S 3}$. HSQC spectra correspond to the color-coded substructures. Figure $\mathbf{S 4}$. Relative abundances in lignin interunit linkages in switchgrass EMAL and $\mathrm{L}_{1}$. Figure. S5. Optimized geometries of dilignol with IL complexes. (DOCX $697 \mathrm{~kb}$ ).

\section{Abbreviations}

IL: ionic liquid; [TBA]: tetrabutylammonium; [OH]: hydroxide; $\left[\mathrm{C}_{2} \mathrm{C}_{1} \mathrm{Im}\right][\mathrm{OAc}]$ : 1-ethyl-3-methylimidazolium acetate; [TBA]F: tetrabutylammonium fluoride trihydrate; [TEA]Cl: tetraethylammonium chloride; [TBA][OAc]: tetrabutylammonium acetate; DMSO: dimethyl sulfoxide; [TBP][OH]: tetrabutylphosphonium hydroxide; XRD: X-ray diffraction; EMAL: enzymatic mild acid lignin; HSQC: heteronuclear single quantum coherence; NMR: nuclear magnetic resonance; SEC: size exclusion chromatography; GPC: gel permeation chromatography; BSSE: basis set superposition error.

\section{Authors' contributions}

RP and SS designed and coordinated the study; JS, TD, and NS conducted the biomass experiments. SP and AGP conducted glycome profiling experiments. MK conducted techno economic analysis. RPS, JS, TD, NS, SP, MK, BAS and SS carried out data analysis and wrote the manuscript. All authors read and approved the final manuscript.

\section{Author details}

${ }^{1}$ Deconstruction Division, Joint BioEnergy Institute, Emeryville, CA 94608, USA. ${ }^{2}$ Sandia National Laboratories, Biological and Engineering Sciences Center, Livermore, CA, USA. ${ }^{3}$ Complex Carbohydrate Research Center, University of Georgia, Athens, GA 30602, USA. ${ }^{4}$ Oak Ridge National Laboratory, The BioEnergy Science Center, Oak Ridge, TN 37831, USA.

\section{Acknowledgements}

This work was part of the DOE Joint BioEnergy Institute (http://www.jbei.org) supported by the U. S. Department of Energy, Office of Science, Office of Biological and Environmental Research, through contract DE-AC02-05CH11231 between Lawrence Berkeley National Laboratory and the U. S. Department of Energy. The United States Government retains and the publisher, by accepting 
the article for publication, acknowledges that the United States Government retains a nonexclusive, paid-up, irrevocable, world wide license to publish or reproduce the published form of this manuscript, or allow others to do so, for United States Government purposes. This research used resources of the National Energy Research Scientific Computing Center (NERSC) and EMSL at Pacific Northwest National Laboratory. The glycome profiling was supported by the BioEnergy Science Center administered by Oak Ridge National Laboratory, and Funded by a Grant (DE-AC05-00OR22725) from the Office of Biological and Environmental Research, Office of Science, United States, Department of Energy. The generation of the CCRC series of plant cell wall glycan-directed monoclonal antibodies used in this work was supported by the NSF Plant Genome Program (DBI-0421683 and IOS-0923992). The authors would also like to thank Novozymes for their generous donation of Ctec 2 and Htec2 enzymes.

\section{Competing interests}

The authors declare that they have no competing interests.

\section{Availability of supporting data}

$X$-ray diffraction patterns, detailed lignin analysis and glycome profiling experiments are given as supporting document.

\section{Consent for publication}

All the authors consented on the publication of this work.

\section{Ethical approval and consent to participate}

All authors have approved the manuscript and agree with submission to Biotechnology for Biofuels.

\section{Funding}

U. S. Department of Energy, Office of Science, Office of Biological and Environmental Research: DE-AC02-05CH1 1231 and DE-AC05-00OR22725. NSF Plant Genome Program: DBI-0421683 and IOS-0923992.

Received: 23 May 2016 Accepted: 12 July 2016

Published online: 02 August 2016

\section{References}

1. Canadell JG, Schulze ED. Global potential of biospheric carbon management for climate mitigation. Nat Commun. 2014;5:1-12.

2. Schubert C. Can biofuels finally take center stage? Nat Biotechnol. 2006:24(7):777-84.

3. Tanger P, Field JL, Jahn CE, DeFoort MW, Leach JE. Biomass for thermochemical conversion: targets and challenges. Front Plant Sci. 2013;4(218):1-20.

4. Wyman CE. Aqueous pretreatment of plant biomass for biological and chemical conversion to fuels and chemicals. New York: Wiley; 2013.

5. Himmel ME, et al. Biomass recalcitrance: engineering plants and enzymes for biofuels production. Science. 2007;315(5813):804-7.

6. Wyman $\mathrm{CE}$, et al. Coordinated development of leading biomass pretreatment technologies. Bioresour Technol. 2005;96(18):1959-66.

7. Kumar P, Barrett DM, Delwiche MJ, Stroeve P. Methods for pretreatment of lignocellulosic biomass for efficient hydrolysis and biofuel production. Ind Eng Chem Res. 2009;48(8):3713-29.

8. Yang B, Wyman CE. Pretreatment: the key to unlocking low-cost cellulosic ethanol. Biofuel Bioprod Biorefin. 2008;2(1):26-40.

9. Balan V, Bals B, Chundawat SS, Marshall D, Dale B. Lignocellulosic biomass pretreatment using AFEX. In: Mielenz JR, editor. Biofuels, vol. 581. New York: Humana Press; 2009. p. 61-77.

10. Li C, et al. Comparison of dilute acid and ionic liquid pretreatment of switchgrass: biomass recalcitrance, delignification and enzymatic saccharification. Bioresour Technol. 2010;101(13):4900-6.

11. Sendich $E$, et al. Recent process improvements for the ammonia fiber expansion (AFEX) process and resulting reductions in minimum ethanol selling price. Bioresour Technol. 2008;99(17):8429-35.

12. Singh S, Simmons BA, Vogel KP. Visualization of biomass solubilization and cellulose regeneration during ionic liquid pretreatment of switchgrass. Biotechnol Bioeng. 2009;104(1):68-75.
13. Tao $L$, et al. Process and technoeconomic analysis of leading pretreatment technologies for lignocellulosic ethanol production using switchgrass. Bioresour Technol. 2011;102(24):11105-14.

14. Uppugundla $\mathrm{N}$, et al. A comparative study of ethanol production using dilute acid, ionic liquid and $\mathrm{AFEX}^{\mathrm{TM}}$ pretreated corn stover. Biotechnol Biofuels. 2014;7:72.

15. Dutta T, et al. CHAPTER 3 ionic liquid pretreatment of lignocellulosic biomass for biofuels and chemicals. In: lonic liquids in the biorefinery concept: challenges and perspectives. The Royal Society of Chemistry, 2016, pp 65-94.

16. Li W, et al. Rapid dissolution of lignocellulosic biomass in ionic liquids using temperatures above the glass transition of lignin. Green Chem. 2011;13(8):2038-47.

17. Tsao GT. Recent progress in bioconversion of lignocellulosics, vol. 65. New York: Springer; 1999.

18. Debzi E, Chanzy H, Sugiyama J, Tekely P, Excoffier G. The la $\rightarrow$ I $\beta$ transformation of highly crystalline cellulose by annealing in various mediums. Macromolecules. 1991;24(26):6816-22.

19. Brandt A, Grasvik J, Hallett JP, Welton T. Deconstruction of lignocellulosic biomass with ionic liquids. Green Chem. 2013;15(3):550-83.

20. Shi J, et al. Impact of mixed feedstocks and feedstock densification on ionic liquid pretreatment efficiency. Biofuels. 2013;4(1):63-72.

21. Sun $\mathrm{N}$, et al. Understanding pretreatment efficacy of four cholinium and imidazolium ionic liquids by chemistry and computation. Green Chem. 2014;16(5):2546-57.

22. Singh S, Simmons BA. lonic liquid pretreatment: mechanism, performance, and challenges. In: Aqueous pretreatment of plant biomass for biological and chemical conversion to fuels and chemicals. Wiley, Amsterdam, 2013, pp 223-38.

23. Fukaya Y, Hayashi K, Wada M, Ohno H. Cellulose dissolution with polar ionic liquids under mild conditions: required factors for anions. Green Chem. 2008;10(1):44-6.

24. Shi J, et al. Understanding the role of water during ionic liquid pretreatment of lignocellulose: co-solvent or anti-solvent? Green Chem. 2014;16(8):3830-40.

25. Parthasarathi $R$, et al. Theoretical insights into the role of water in the dissolution of cellulose using IL/water mixed solvent systems. J Phys Chem B. $2015 ; 119(45): 14339-49$.

26. Li L, Yu S-T, Liu F-S, Xie C-X, Xu C-Z. Efficient enzymatic in situ saccharification of cellulose in aqueous-ionic liquid media by microwave pretreatment. BioResources. 2011;6(4):4494-504.

27. Zhou S, Liu L, Wang B, Xu F, Sun RC. Biodiesel preparation from transesterification of glycerol trioleate catalyzed by basic ionic liquids. Chin Chem Lett. 2012;23(4):379-82.

28. Qu Y, et al. One-pot conversion of disaccharide into 5-hydroxymethylfurfural catalyzed by imidazole ionic liquid. Sci Rep. 2016;6:1-7.

29. Heinze T, et al. Effective preparation of cellulose derivatives in a new simple cellulose solvent. Macromol Chem Phys. 2000;201(6):627-31.

30. Changfa X. Investigation on dissolution mechanism of cellulose in tetraethylammonium chloride/dimethyl sulfoxide. Spectroscopy and Spectral Analysis. 1994; 4.

31. Ema T, Komiyama T, Sunami S, Sakai T. Synergistic effect of quaternary ammonium hydroxide and crown ether on the rapid and clear dissolution of cellulose at room temperature. RSC Adv. 2014;4(5):2523-5.

32. Miao J, Sun H, Yu Y, Song X, Zhang L. Quaternary ammonium acetate: an efficient ionic liquid for the dissolution and regeneration of cellulose. RSC Adv. 2014;4(69):36721-4.

33. Hyväkkö U, King AW, Kilpeläinen I. Extraction of wheat straw with aqueous tetra- $n$-butylphosphonium hydroxide. BioResources. 2014;9(1):1565-77.

34. Abe M, Fukaya Y, Ohno H. Fast and facile dissolution of cellulose with tetrabutylphosphonium hydroxide containing 40 wt\% water. Chem Commun. 2012;48(12):1808-10.

35. Zhong C, Wang C, Huang F, Jia H, Wei P. Wheat straw cellulose dissolution and isolation by tetra-n-butylammonium hydroxide. Carbohydr Polym. 2013;94(1):38-45

36. Klein-Marcuschamer D, Simmons BA, Blanch HW. Techno-economic analysis of a lignocellulosic ethanol biorefinery with ionic liquid pretreatment. Biofuel Bioprod Biorefin. 2011;5(5):562-9.

37. Ferlin N, et al. Biomass derived ionic liquids: synthesis from natural organic acids, characterization, toxicity, biodegradation and use 
as solvents for catalytic hydrogenation processes. Tetrahedron. 2013;69(30):6150-61.

38. Cheng $\mathrm{G}$, et al. Impact of ionic liquid pretreatment conditions on cellulose crystalline structure using 1-ethyl-3-methylimidazolium acetate. Phys Chem B. 2012;116(33):10049-54.

39. Mansikkamäki P, Lahtinen M, Rissanen $K$. Structural changes of cellulose crystallites induced by mercerisation in different solvent systems; determined by powder X-ray diffraction method. Cellulose. 2005;12(3):233-42.

40. Park S, Baker JO, Himmel ME, Parilla PA, Johnson DK. Research cellulose crystallinity index: measurement techniques and their impact on interpreting cellulase performance. Biotechnol Biofuels. 2010;3(10):1.

41. Socha AM, et al. Efficient biomass pretreatment using ionic liquids derived from lignin and hemicellulose. Proc Natl Acad Sci. 2014;111(35):E3587-95.

42. Wu S, Argyropoulos D. An improved method for isolating lignin in high yield and purity. J Pulp Pap Sci. 2003;29(7):235-40.

43. Bunzel M, Ralph J. NMR characterization of lignins isolated from fruit and vegetable insoluble dietary fiber. J Agric Food Chem. 2006;54(21):8352-61.

44. Ibarra D, et al. Structural modification of eucalypt pulp lignin in a totally chlorine-free bleaching sequence including a laccase-mediator stage. Holzforschung. 2007;61 (6):634-46.

45. Ibarra D, et al. Lignin modification during Eucalyptus globulus kraft pulping followed by totally chlorine-free bleaching: a two-dimensional nuclear magnetic resonance, Fourier transform infrared, and pyrolysisgas chromatography/mass spectrometry study. J Agric Food Chem. 2007;55(9):3477-90

46. Kim H, Ralph J. Solution-state 2D NMR of ball-milled plant cell wall gels in DMSO-d6/pyridine-d5. Org Biomol Chem. 2010;8(3):576-91.

47. Kim H, Ralph J, Akiyama T. Solution-state 2D NMR of ball-milled plant cell wall gels in DMSO-d 6. BioEnergy Res. 2008;1 (1):56-66.

48. Thygesen A, Oddershede J, Lilholt H, Thomsen AB, Ståhl K. On the determination of crystallinity and cellulose content in plant fibres. Cellulose. 2005;12(6):563-76.

49. Yelle DJ, Ralph J, Frihart CR. Characterization of nonderivatized plant cell walls using high-resolution solution-state NMR spectroscopy. Magn Reson Chem. 2008:46(6):508.

50. Argyropoulos DS, et al. Abundance and reactivity of dibenzodioxocins in softwood lignin. J Agric Food Chem. 2002;50(4):658-66.

51. Wen J-L, Sun S-L, Xue B-L, Sun R-C. Recent advances in characterization of lignin polymer by solution-state nuclear magnetic resonance (NMR) methodology. Materials. 2013;6(1):359-91.

52. Pattathil $\mathrm{S}$, et al. Changes in cell wall carbohydrate extractability are correlated with reduced recalcitrance of HCT downregulated alfalfa biomass. Ind Biotechnol. 2012;8(4):217-21.
53. Medronho B, Lindman B. Competing forces during cellulose dissolution: from solvents to mechanisms. Curr Opin Colloid Interface Sci. 2014;19(1):32-40.

54. MacFarlane DR, Seddon KR. Ionic liquids_-progress on the fundamental issues. Aust J Chem. 2007;60(1):3-5.

55. Pedersen M, Meyer AS. Lignocellulose pretreatment severity: relating $\mathrm{pH}$ to biomatrix opening. N Biotechnol. 2010;27(6):739-50.

56. Cruz H, Fanselow M, Holbrey JD, Seddon KR. Determining relative rates of cellulose dissolution in ionic liquids through in situ viscosity measurement. Chem Commun. 2012:48(45):5620-2.

57. Bhatt VD, Gohil K. Performance evaluation of solar cooker using some [N] based ionic liquids as thermal energy storage materials.

58. Park S, Baker JO, Himmel ME, Parilla PA, Johnson DK. Cellulose crystallinity index: measurement techniques and their impact on interpreting cellulase performance. Biotechnol Biofuels. 2010;3(1):1.

59. Ragauskas A, et al. Structural characterization of lignin in wild-type versus COMT down-regulated switchgrass. Front Energy Res. 2014;1:14.

60. Boys SF, Bernardi F. Calculation of small molecular interactions by differences of separate total energies: some procedures with reduced errors. Mol Phys. 1970;19(4):553-66.

61. Gaussian 09 RA, Frisch MJ, Trucks GW, Schlegel HB, Scuseria GE, Robb MA, Cheeseman JR, Scalmani G, Barone V, Mennucci B, Petersson GA, Nakatsuji H, Caricato M, Li X, Hratchian HP, Izmaylov AF, Bloino J, Zheng G, Sonnenberg JL, Hada M, Ehara M, Toyota K, Fukuda R, Hasegawa J, Ishida M, Nakajima T, Honda Y, Kitao O, Nakai H, Vreven T, Montgomery Jr. JA, Peralta JE, Ogliaro F, Bearpark M, Heyd JJ, Brothers E, Kudin KN, Staroverov VN, Kobayashi R, Normand J, Raghavachari K, Rendell A, Burant JC, lyengar SS, Tomasi J, Cossi M, Rega N, Millam NJ, Klene M, Knox JE, Cross JB, Bakken V, Adamo C, Jaramillo J, Gomperts R, Stratmann RE, Yazyev O, Austin AJ, Cammi R, Pomelli C, Ochterski JW, Martin RL, Morokuma K, Zakrzewski VG, Voth GA, Salvador P, Dannenberg JJ, Dapprich S, Daniels AD, Farkas Ö, Foresman JB, Ortiz JV, Cioslowski J, Fox DJ. Gaussian, Inc., Wallingford CT, 2009.

62. DeMartini JD, et al. Application of monoclonal antibodies to investigate plant cell wall deconstruction for biofuels production. Energy Environ Sci. 2011;4(10):4332-9.

63. Pattathil S, Avci U, Miller JS, Hahn MG. Immunological approaches to plant cell wall and biomass characterization: glycome profiling. Biomass Conversion. Springer, New York, 2012, pp 61-72.

64. Pattathil S, et al. A comprehensive toolkit of plant cell wall glycandirected monoclonal antibodies. Plant Physiol. 2010;153(2):514-25.

\section{Submit your next manuscript to BioMed Central and we will help you at every step:}

- We accept pre-submission inquiries

- Our selector tool helps you to find the most relevant journal

- We provide round the clock customer support

- Convenient online submission

- Thorough peer review

- Inclusion in PubMed and all major indexing services

- Maximum visibility for your research

Submit your manuscript at www.biomedcentral.com/submit 